Bull. Mater. Sci., Vol. 2, Number 1. January 1980, pp. 43-53. (C) Printed in India.

\title{
Microhardness studies in ammonium halide crystals
}

\author{
K I PRATAP and V HARI BABU \\ Department of Physics, College of Science, Osmania University, Hyderabad 500007 \\ MS received 12 October 1979

\begin{abstract}
Microhardness studies of $\mathrm{NH}_{4} \mathrm{Cl}$ (pure and doped), $\mathrm{NH}_{4} \mathrm{Br}$ and alkali halide crystals are presented. The hardness of ammonium halides is found to be less as compared to alkali halide crystals. Doping $\mathrm{NH}_{4} \mathrm{Cl}$ crystals with copper $\left(\mathrm{Cu}^{2+}\right)$ is found to increase the hardness enormously and the results obtained with various concentrations of copper are presented. The results have been analysed and the various factors contributing to the increase in hardness at lower loads have been discussed.
\end{abstract}

Keywords. Microhardness ; Rosette pattern ; doping; monovalent impuritiesdivalent impurities; dislocations.

\section{Introduction}

Considerable work has been done on the meshanical properties of alkali halide crystals. The effect of monovalent and divalent impurities on hardness has been investigated. The experiments showed that small concentrations of divalent metal impurity ions would greatly harden the alkali halides as compared to monovalent ions (Blank and Smekel 1930; Johnston 1962; Dryden et al 1965; Newey et al 1966; Chin et al 1973; Labenets and Startsev 1968). It has also been observed that if the impurity concentration exceeds the solubility limit, visible precipitates are formed and further additions of the impurity will not contribute further to hardness. Microstructural and hardness studies on $\mathrm{KCl}$ crystals doped with alkaline earth impurities have shown that dislocations act as nucleation sites for the formation of large visible precipitates and that the state of dispersion of the impurity plays an important role in determining the hardness of crystals (Lakshmipathi Rao and Hari Babu 1978).

On the other hand monovalent ions can be substitutionally dissolved in alkali halide crystals to a much higher extent than divalent ions. Especially, if the difference between the solute and solvent is not large, any content of composition keeps equilibrium at room temperature (Fancher and Borsch 1969). On the strength of the materials some experimental results are available for $\mathrm{KCl}-\mathrm{KBr}$ (Stoloff et al 1963) and $\mathrm{NaCl}-\mathrm{NaBr}$ (Wimmer et al 1963) systems showing a solid solution hardening or softening and for $\mathrm{NaCl}-\mathrm{AgCl}$ (Stokes and $\mathrm{Li}$ 1962) and $\mathrm{NaCl}-\mathrm{KCl}$ (Wolfson et al 1966) systems showing a precipitation hardening. Recent microhardness studies in alkali halide mixed crystals (Subba Rao and Hari Babu 1978) 
showed that it varies nonlinearly with composition. Kataokov and Yamada (1977) have studied the yield strength and dislocation mobility of $\mathrm{KCl}-\mathrm{KBr}$ solid solution single crystals. They have proposed an analytical model of the hardening mechanism on the basis of elastic interaction (size misfit) between an edge dislocation and solute atoms. Uematru et al (1978) also studied solution hardening and softening in $\mathrm{KCl}-\mathrm{KBr}$ single crystals at low temperatures. From the analysis of activation volume, they concluded that the dislocation motion in the higher concentration region was impeded only by the solute ions and that in the lower concentration region by Peirerls barriers in addition to the solute ions.

It is thus clear that considerable work has been done in alkali halide crystals and the mechanism of hardening is fairly well understood. However, there is practically no work on the mechanical properties of $\mathrm{NH}_{4} \mathrm{Cl}$ crystals. This paper presents results of microhardness studies on $\mathrm{NH}_{4} \mathrm{Cl}, \mathrm{NH}_{4} \mathrm{Br}$ and $\mathrm{NH}_{4} \mathrm{Cl}$ crystals doped with various concentrations of copper chloride. Microhardness results of some alkali halide crystals are also given for comparison. The dependence of microhardness on load has been analysed and various factors contributing to the increase in hardness at lower loads have been discussed.

\section{Experimental}

Single crystals of pure and coppen doped $\mathrm{NH}_{4} \mathrm{Cl}$ crystals used in the present investigation are grown by slow evaporation of saturated aqueous solutions containing urea. Alkali halide crystals have been grown from the melt by the Kyroupolos technique (Subba Rao and Hari Babu 1978). Microhardness measurements have been made by Vicker's indenton attached to a microscope as grown crystals. The microhardness is calculated using the expression $H=1.8544 P / d^{2}$ where $P$ is the load applied in grams and $d$ is the length of the diagonal of the indentor impression in microns. All indentations have been made at room temperature and the time of indentation has been kept at $10 \mathrm{sec}$. On each sample at least ten indentations have been made and the final value of the microhardness is the average value of all such measurements.

\section{Results}

$\mathrm{NH}_{4} \mathrm{Cl}$ crystals cannot be cleaved easily and indentations have therefore been made on naturally grown cubic faces. Snooth surface is selected before indentation. The impressions obtained on $\mathrm{NH}_{4} \mathrm{Cl}$ crystals after indenting with $1 \cdot 25 \mathrm{P}$ and $60 \mathrm{P}$ loads are shown in figure 1 . The size of the impression increases with load.

The microhardness vaiues of $\mathrm{NaCl}, \mathrm{KCl}$ and $\mathrm{KBr}$ obtained at a load of $40 \mathrm{P}$ are given in tab'e 1 and those of $\mathrm{NH}_{4} \mathrm{Cl}, \mathrm{NH}_{4} \mathrm{Br}$ and copper chloride $\left(\mathrm{Cu}^{2+}\right)$ doped $\mathrm{NH}_{4} \mathrm{Cl}$ crysta's are given in table 2. The results show that ammonium halide crystals are more soft as compared to alkali halide crystals. Doping $\mathbf{N H}_{4} \mathrm{Cl}$ crystals with coppen chloride $\left(\mathrm{Cu}^{2+}\right)$ considerably increases the hardness. The variation of hardness with concentration of $\mathrm{Cu}^{2+}$ is illustrated in figure 2 , which shows that for small additions of $\mathrm{Cu}^{2+}$ the increase in hardness is large and at higher concentration the hardiness tends to saturate. 


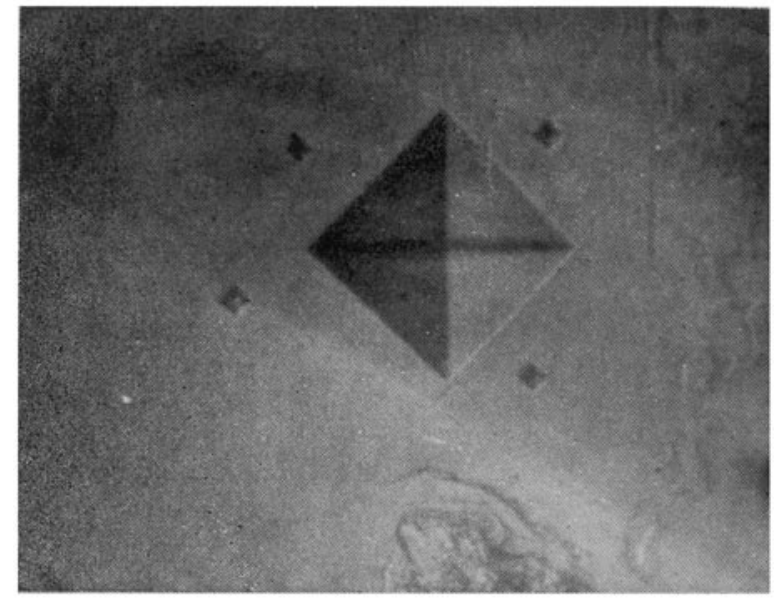

Figure 1. Indentor impressions at lower and higher loads ( $\times 150)$. 

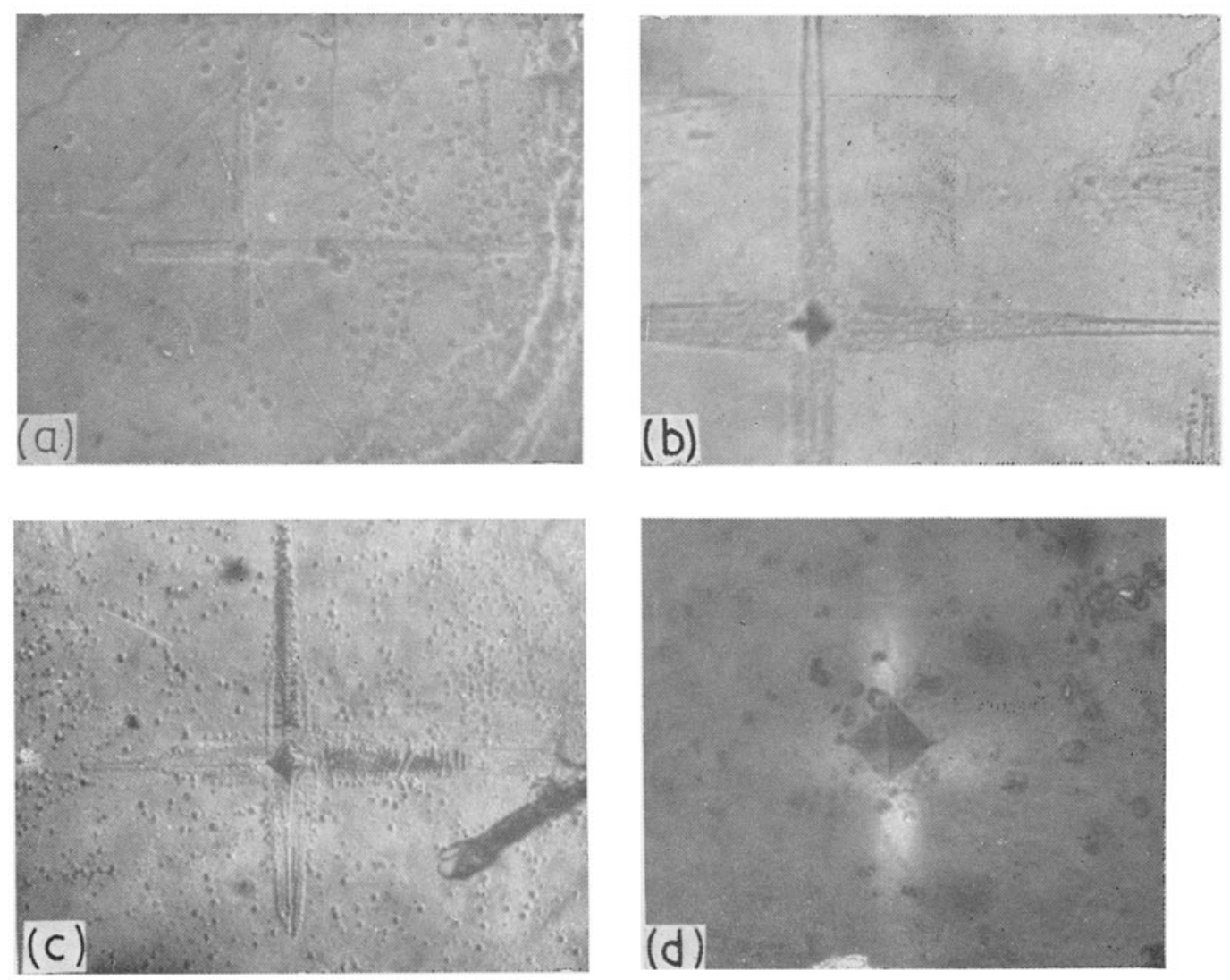

Figure 3. Rosette patterns obtained on undoped and doped $\mathrm{NH}_{4} \mathrm{Cl}$ crystals after etching. (a) Indentor Load 1.25 P, (b) Indentor Load $10 \mathrm{P}$, (c) Load $10 \mathrm{P}$, (d) Strain pattern obtained after placing the indented copper doped $\mathrm{NH}_{4} \mathrm{Cl}$ crystal between crossed nicols. 
Table 1. Hardness data for few alkali halide crystals.

\begin{tabular}{cccc}
\hline Crystal & $\begin{array}{c}\text { Hardness } \\
\text { (Present } \\
\text { work) } \\
\mathrm{kg} / \mathrm{mm}^{2}\end{array}$ & $\begin{array}{c}\text { Hardness } \\
\text { (Chin } \\
\text { et al 1972) } \\
\mathrm{kg} / \mathrm{mm}^{2}\end{array}$ & $\begin{array}{c}\text { Hardness } \\
\text { (Hopkins } \\
\text { et al 1933) } \\
\mathrm{kg} / \mathrm{mm}^{2}\end{array}$ \\
\hline $\mathrm{NaCl}$ & 19.6 & $18 \cdot 2$ & $18 \cdot 5$ \\
$\mathrm{KCl}$ & 10.0 & $9 \cdot 3$ & $9 \cdot 2$ \\
$\mathrm{KBr}$ & 9.37 & 7.0 & $\ldots$ \\
\hline
\end{tabular}

Table 2. Vickers hardness data for $\mathrm{NH}_{4} \mathrm{Cl}, \mathrm{NH}_{4} \mathrm{Cl}, \mathrm{NH}_{4} \mathrm{Br}$ and copper doped $\mathrm{NH}_{4} \mathrm{Cl}$.

\begin{tabular}{|c|c|c|}
\hline Crystal & $\begin{array}{c}\text { Concentration } \\
\text { of copper in } \\
\text { mol. } \%\end{array}$ & $\begin{array}{l}\text { Hardness } \\
\left(\mathrm{kg} / \mathrm{mm}^{2}\right)\end{array}$ \\
\hline $\mathrm{NH}_{4} \mathrm{Cl}$ & . & $2 \cdot 5$ \\
\hline $\mathrm{NH}_{4} \mathrm{Br}$ & $\ldots$ & $2 \cdot 4$ \\
\hline $\mathrm{Cu}-\mathrm{NH}_{4} \mathrm{Cl}$ & $0 \cdot 1$ & $16 \cdot 2$ \\
\hline $\mathrm{Cu}-\mathrm{NH}_{4} \mathrm{Cl}$ & 0.2 & $20 \cdot 8$ \\
\hline $\mathrm{Cu}-\mathrm{NH}_{4} \mathrm{Cl}$ & $0 \cdot 4$ & $22 \cdot 6$ \\
\hline $\mathrm{Cu}-\mathrm{NH}_{4} \mathrm{Cl}$ & 0.5 & $23 \cdot 6$ \\
\hline $\mathrm{Cu}-\mathrm{NH}_{4} \mathrm{Cl}$ & $1 \cdot 5$ & $28 \cdot 3$ \\
\hline $\mathrm{Cu}-\mathrm{NH}_{4} \mathrm{Cl}$ & $3 \cdot 0$ & $32 \cdot 0$ \\
\hline $\mathrm{Cu}-\mathrm{NH}_{4} \mathrm{Cl}$ & $5 \cdot 0$ & $36 \cdot 4$ \\
\hline
\end{tabular}

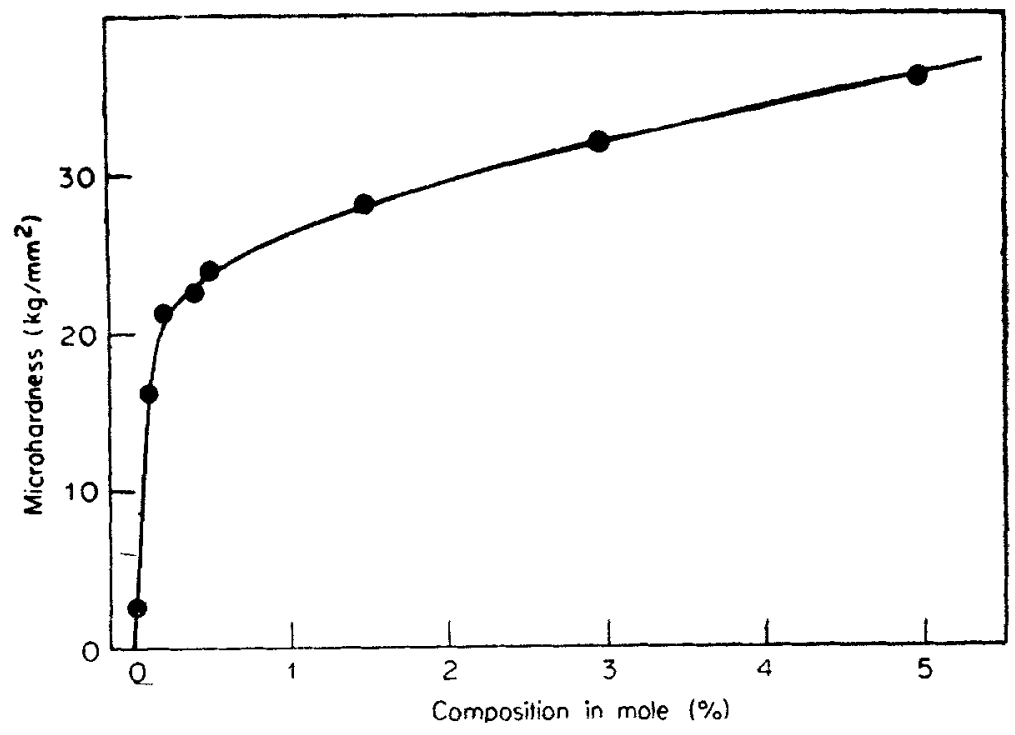

Figure 2. Variation of microhardness with composition of copper (in $\mathrm{mol}, \%$ ) in $\mathrm{NH}_{4} \mathrm{Cl}$ crystals. 
It was earlier shown that the size of the dislocation of rosette produced around a microhardness indentation is a useful and convenient test for determining mechanical strength of single crystals (Davison and Vaughan 1958). The dislocation rosette around the indentations were revealed by etching the crystals in an etchant consisting of methanol to which cadmium chloride is added as poison. Figures 3 (a) and 3 (b) show the photomicrographs of 'Rosette' patterns obtained on $\mathrm{NH}_{4} \mathrm{Cl}$ crystals with $1.25 \mathrm{P}$ and $10 \mathrm{P}$ loads, respectively. The pattern obtained at a load of $10 \mathrm{P}$ in the case of $\mathrm{NH}_{4} \mathrm{Cl}$ doped with $1.5 \mathrm{~mol} \%$ coppen chloride $\left(\mathrm{Cu}^{2+}\right)$ is shown in figure $3(\mathrm{c})$. It is seen that the wing lengths which corresponds to the distance travelled by the dislocation decrease as the hardness increases and so in harder crystals the distance travelled is less. The figure also shows that the dislocations in $\mathrm{NH}_{4} \mathrm{Cl}$ are propagated along $\langle 100\rangle$ directions. The indentations produce strains in the crystal and these have been observed by placing the crystal in crossed nicols. Figure $3(\mathrm{~d})$ is a photomicrograph obtained on $\mathrm{NH}_{4} \mathrm{Cl}$ crystal doped with $5 \mathrm{~mol} \%$. copper chloride. It is seen that maximum strains are produced along $\langle 100\rangle$ direction, the direction along which the dislocations have moved.

Upit and Varchenya (1965) and Buckle (1945) have reported earlier that the hardness number gradually increases as load decreases. The microhardness value obtained at different loads for $\mathrm{NH}_{4} \mathrm{Cl}$ and $\mathrm{NH}_{4} \mathrm{Br}$ are shown in figure 4 . The values obtained for $\mathrm{NaCl}, \mathrm{KCl}$ and $\mathrm{KBr}$ are shown in figure 5 and those for $\mathrm{NH}_{4} \mathrm{Cl}$ crystals doped with $1 \cdot 5,3$ and $5 \mathrm{~mol} \%$ of $\mathrm{Cu}^{2+}$ are shown in figure 6.

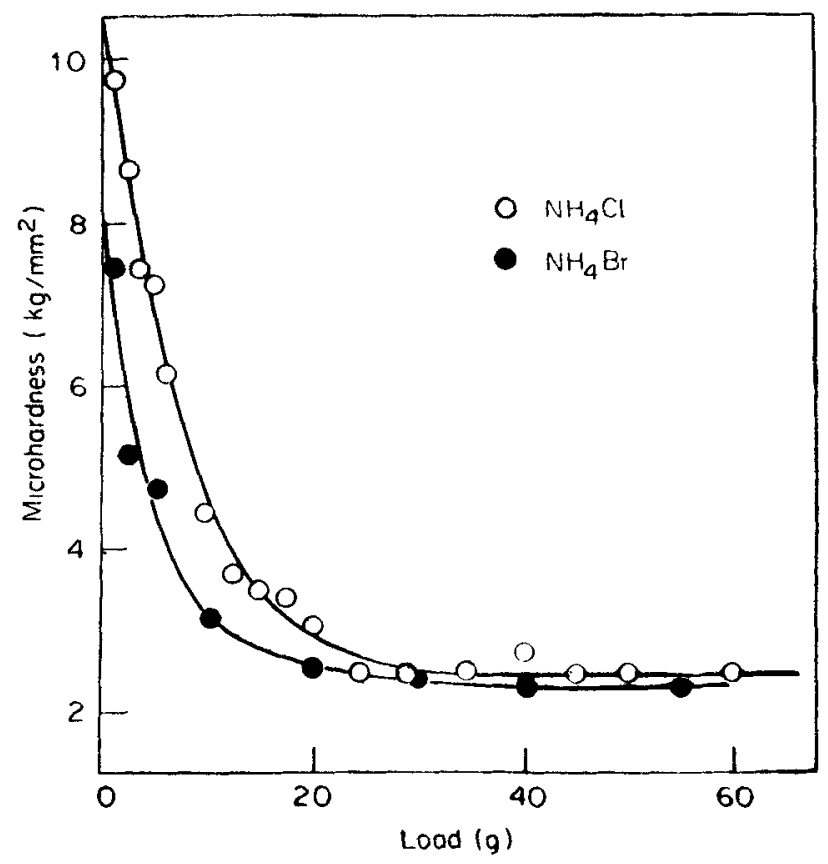

Figure 4, Variation of microhardness with load for $\mathrm{NH}_{4} \mathrm{Cl}$ and $\mathrm{NH}_{4} \mathrm{Br}$ crystals. 


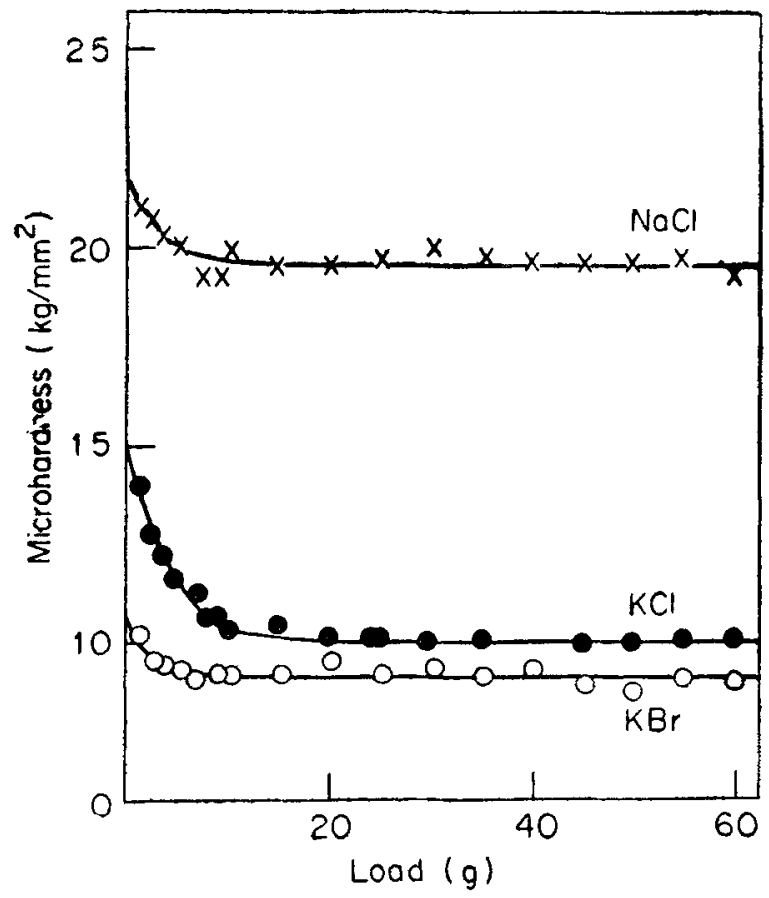

Figure 5. Variation of microhardness with load for $\mathrm{NaCl}, \mathrm{KCl}$ and $\mathrm{KBr}$ crystals.

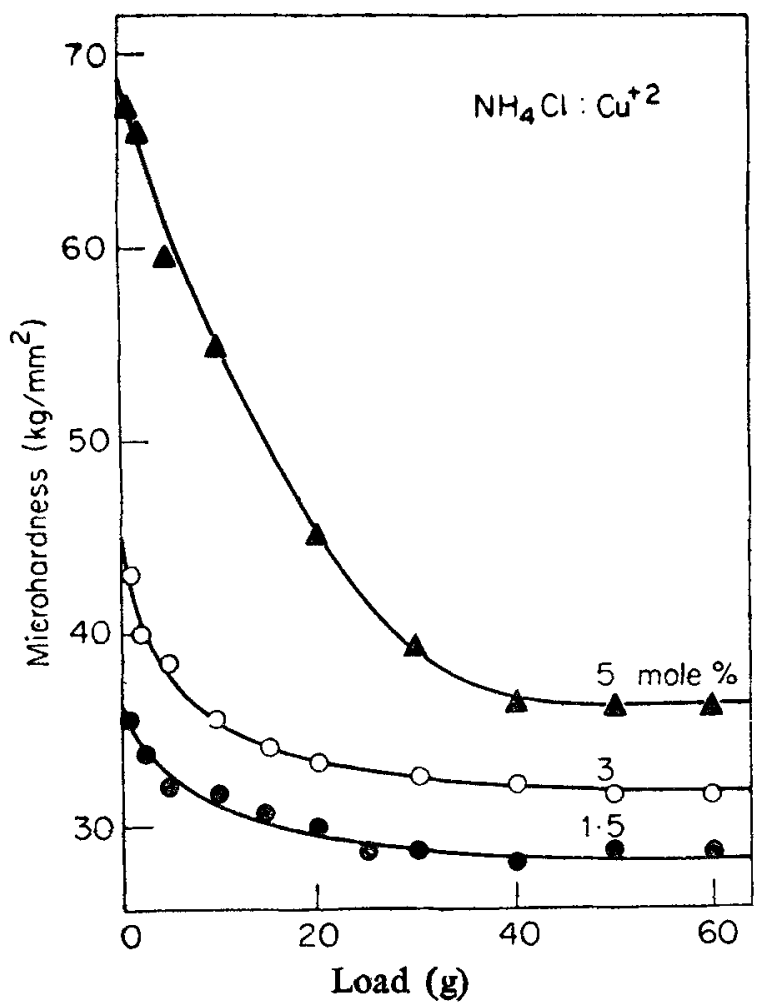

Figure 6. Variation of microhardness with load for copper-doped $\mathrm{NH}_{4} \mathrm{Cl}$ crystals, 


\section{Discussion}

The results presented in figures 4,5 and 6 show that as load decreases, the hardness increases. Upit and Varchanya (1966) have obtained similar results in alkali halide crystals, and they interpreted their results as due to the effect of the surface on the mechanical properties of bulk. On the other hand, Hays and Kendall (1973) who obtained similar results in a number of metals and alloys adopted a different approach to explain their results and this method is used to analyse our results. Earlier Kick (1885) proposed an analysis of hardness and according to this the relation between load $P$ and indentation length $d$ is given as

$$
P=K_{1} d^{n},
$$

where $P$ is the applied load in $\mathrm{kg}, d$ is the observed length of indentation (mm), $K_{1}$ and $n$ are constants. Kick's analysis for hardness postulates a constant value of $n=2$ for all indentors and for all impressions geometrically similar to each other. Equation (1) was further corroborated (Schultz and Hanemann 1941) when they proposed that Vicker's microhardness and macrohardness values were comparable. However Kick's law (equation (1)) has not been widley accepted due to the fact that $n$ usually has a value less than 2, especially in the low load hardness region. In order to overcome this difficulty Hays and Kendall (1973) assumed that a portion of resistance to deformation could be evaluated by considering it as a Newtonian resultant pressure of the specimen itself. As a load $P$ is applied to a sample, it was assumed that $P$ is partially affected by a smaller resultant pressure $W$ which is a function of the material being tested. According to Hays and Kendall (1973) $W$ represents the minimum applied load to cause an indentation as load $W$ will allow no plastic deformation.

If equation (1) is reconsidered on the basis of the sample's resistance pressure $W$, it follows that

$$
P-W=K_{2} d^{2},
$$

where $K_{2}$ is constant, and $n=2$ is the logarithemic index. In this case $n$ should be equal to 2 , since it is proposed that the factor $W$ allows the limiting case to prevail where hardness is not markedly dependent on the load. To evaluate the fraction $W$ for a particular solution, it is feasible to solve the two equations by subtraction, thus

$$
\begin{aligned}
W & =K_{1} d^{n}-K_{2} d^{2}, \\
d^{n} & =W / K_{1}+K_{2} / K_{1} d^{2} .
\end{aligned}
$$

From this point the analysis is completed by simple graphical methods. A logarithmic study of equation (1) shows that the values of $n$ and $K_{1}$ for any set of descrete data can be obtained from a plot of $\log P$ against $\log d$. The index $n$ is of course the slope while $K_{1}$ is defined as that particular load $P$ which exists at $d=150 \times$ $10^{-5} \mathrm{~mm}$ (figure 7). Similarly a cartesian plot of equation (4) for $d$ versus $d^{2}$ yields the slope $K_{2} / K_{1}$ and intercept $W / K_{1}$. Since $K_{1}$ is known from the previous logarithimic plot, the solution is simplified. All the key data obtained are shown in table 3. Figure 8 is a plot of $\log (P-W)$ vs $\log d$, from which $n=2$ is obtained. This shows that the idea of resistance pressure proposed by Hays and Kendall (1973) can also be applied to alkali and ammonium halide crystals. 


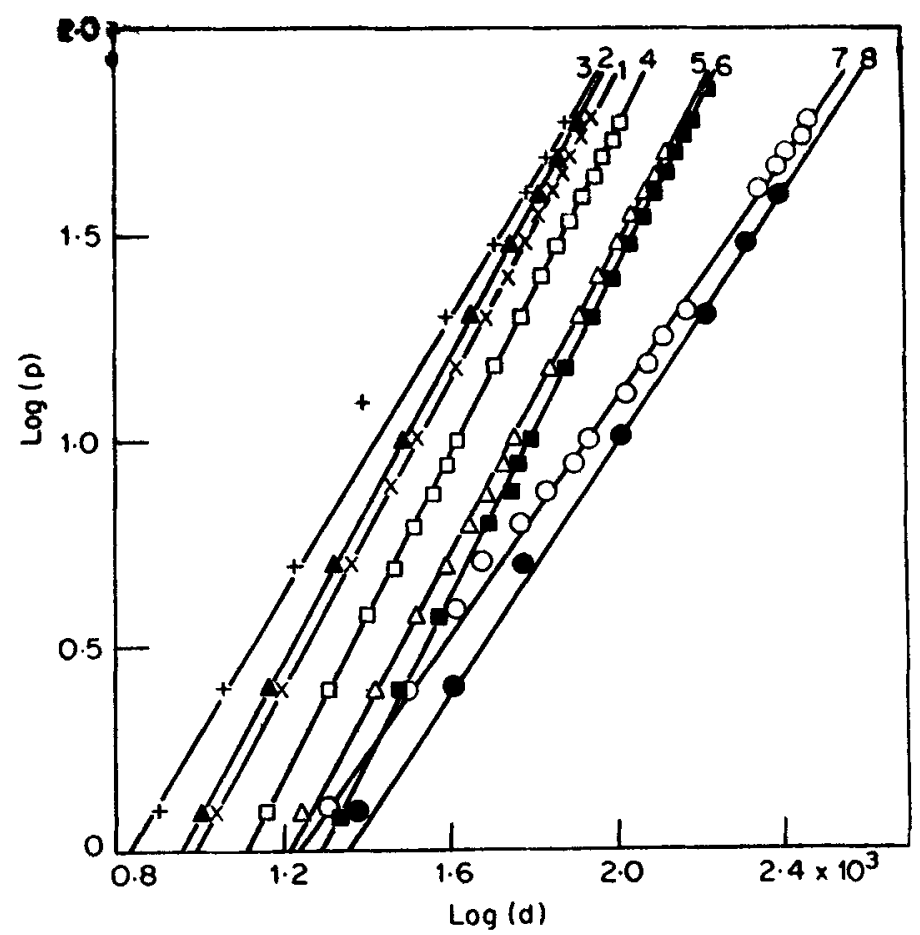

Figure 7. Relationship between the applied $\operatorname{load}(\log P)$ and the Vickers diagonal $(\log d)$ for various crystals.

Table 3. Results of hardness analysis.

\begin{tabular}{|c|c|c|c|c|c|c|}
\hline Crystal & $K_{1}(\mathrm{~kg})$ & $n$ & $W / K_{2}$ & $K_{2} / K_{1}$ & $K_{2}(\mathbf{k g})$ & $\begin{array}{c}W \times 10^{-6} \\
(\mathrm{~kg})\end{array}$ \\
\hline \multicolumn{7}{|l|}{$\mathrm{Cu}-\mathrm{NH}_{4} \mathrm{Cl}$} \\
\hline $\begin{array}{c}(5 \text { mole } \%) \\
\mathrm{Cu}-\mathrm{NH}_{4} \mathrm{Cl}\end{array}$ & 0.01349 & $1 \cdot 6666$ & 0.00070 & $1 \cdot 8181$ & $0 \cdot 06340$ & $9 \cdot 443$ \\
\hline$(3$ mole $\%)$ & $0 \cdot 01122$ & $1 \cdot 8518$ & $0 \cdot 00050$ & $1 \cdot 3333$ & 0.01495 & $5 \cdot 610$ \\
\hline \multicolumn{7}{|l|}{$\mathrm{Cu}-\mathrm{NH}_{4} \mathrm{Cl}$} \\
\hline$(1.5 \mathrm{~mole} \%)$ & 0.00933 & $1 \cdot 8648$ & 0.00140 & $4 \cdot 7000$ & 0.01696 & $13 \cdot 062$ \\
\hline $\mathrm{NaCl}$ & $0 \cdot 00588$ & $1 \cdot 9608$ & $0 \cdot 00080$ & $1 \cdot 2048$ & 0.00709 & $4 \cdot 704$ \\
\hline $\mathbf{K C l}$ & $0 \cdot 00346$ & $1 \cdot 8693$ & $0 \cdot 00032$ & $1 \cdot 9900$ & 0.00689 & $11 \cdot 072$ \\
\hline $\mathbf{K B r}$ & 0.00269 & $1 \cdot 9608$ & $0 \cdot 00100$ & $1 \cdot 2260$ & 0.00330 & $2 \cdot 690$ \\
\hline $\mathrm{NH}_{4} \mathrm{Cl}$ & $0 \cdot 00239$ & $1 \cdot 4286$ & $0 \cdot 00600$ & $32 \cdot 7868$ & 0.07865 & $14 \cdot 340$ \\
\hline $\mathbf{N H}_{4} \mathbf{B r}$ & 0.00169 & $1 \cdot 5335$ & $0 \cdot 00480$ & $14 \cdot 4927$ & 0.02453 & $8 \cdot 112$ \\
\hline
\end{tabular}

Although hardness has been defined in several ways it is now generally accepted that it is the resistance offered to dislocation motion. There are several contributions to the resistance to dislocation motion and they can be classifed broadly into two types (i) the intrinsic resistance and (ii) the resistance due to imperfections. 


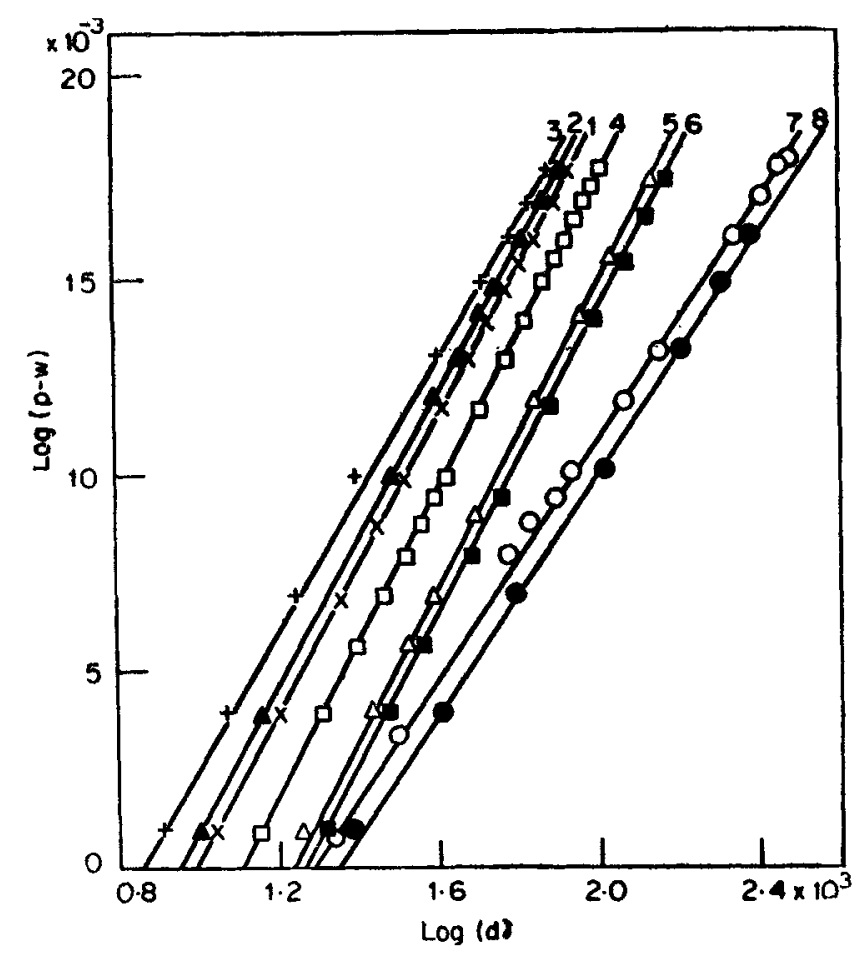

Figure 8. Relationship between true applied $\operatorname{load}(\log P-W)$ and the Vickers diagonal $(\log d)$ for various crystals.

It is well known (Blank and Smekel 1930; Johnston 1962; Dryden et al 1965; Newey et al 1966; Chin et al 1973 and Labenets and Startsev 1968) that dilute additions of divalent impurity has an appreciable effect on the hardness of alkali halide crystals. For each divalent ion introduced into the lattice a positive ion vacancy is formed and these defects are distributed in various ways. The impurity ions and vacancies could be present as impurity-vacancy dipoles or as larger aggregates. All these defects act as obstacles to dislocation motion thus increasing the hardness of the crystals. The experimental results show that doping with copper $\left(\mathrm{Cu}^{2+}\right)$ increases the hardness of $\mathrm{NH}_{4} \mathrm{Cl}$ crystals considerably. This dramatic increase has been explained as due to the tetragonal strains introduced into the lattice by the impurity-vacancy dipoles (Fleicher 1962). The large increase in hardness of $\mathrm{NH}_{4} \mathrm{Cl}$ crystals doped with $\mathrm{Cu}^{2+}$ also may be due to the pressence of impurity vacancy dipoles. At high concentration of impurity, the increase in hardness is not much and this may be due to the association of impurity-vacancy dipoles into larger aggregates as suggested by Dryden et al (1965). The formation of impurity-vacancy dipoles and their aggregation is well known in alkali halide crystals. However, the phenomena have to be confirmed in ammonium halide crystals by some other experiments such as dielectric loss and ionic thermo-currents. 


\section{Acknowledgements}

One of the authors (KJP) thanks the Head of the Department of Physics, Osmania University, for a position under the University Grants Commission Project.

\section{References}

Blank F and Smekel A 1930 Naturwissenschaften 18306

Buckle H 1945 Progress in microindentation hardness testing (Stockholm : Victor Pettersons Bukindustriak tiboday)

Chin G Y, van Uitert L G, Green M L and Zydzik G J 1972 Scr. Metall. 6503

Chin G Y, van Uitert L G, Green M L, Zydzik G J and Kometani T Y $1973 \mathrm{~J}$. Am. Ceram. Soc. 56369

Dryden J S, Morimoto S and Cook J S 1965 Philos. Mag. 12379

Davison J W and Vaughan W H 1958 Rep. Naval Res. Lab. Prog. April 10

Fancher D L and Borsch G R 1969 J. Phys. Chem. Solids 302517

Fleicher R L 1962 Acta Metall. 10835

Hays C and Kendall E G 1973 Metallography 6275

Hopkins J R, Miller J A and Martin J J 1933 Phys. Status Solidi (A) 19591

Johnston W G 1962 J. Appl. Phys. 332050

Kataokov T and Yamada T 1977 Jpn. J. Appl. Phys. 161119

Kick F, Das Gesetzder 1885 Proportionalen winderstande and science anwendung Leipzig Felix (ed.)

Labenets S V and Startsev V I 1968 Sov. Phys. Solid State 1015

Lakshmipathi Rao and Hari Babu V 1978 Indian J. Pure Appl. Phys. 16821

Newey C W A, Harrison R P and Pratt P L 1966 Proc. Br. Ceram. Soc. 6305

Stoloff N S, Lezino D K and Johnston T L 1963 J. Appl. Phys. 343315

Stokes R J and Li C H 1962 Acta Metall. 10535

Subba Rao U V and Hari Babu V 1978 Pramâna 11149

Schultz F and Hanemann H 1941 Z. Metall kd. 33124

Uematru T, Kataokov T and Yamada T 1978 Jpn. J. Appl. Phys. 17271

Upit G P and Varchanya S A 1966 Phys. Status Solidi 17831

Wimmer F T, Kobes W and Fine M E $1963 \mathrm{~J}$. Appl. Phys. 341775

Wolfson R G, Kobes W and Fine M E 1966 J. Appl. Phys. 37704 